\title{
Interaction between warfarin and Chinese herbal medicines
}

\author{
Yan Ting $\underline{\text { Chua }}^{1}$, Xiang Ling $\underline{\text { Ang }}^{2}$, BSc, BMed (TCM), Xi Ming $\underline{\text { Zhong }^{2}}$, Kei Siong ${\underline{K h o 0^{3}}}^{3}$ fRCP, fAMs
}

\begin{abstract}
In traditional Chinese medicine (TCM), the human body is divided into Yin and Yang. Diseases occur when the Yin and Yang balance is disrupted. Different herbs are used to restore this balance, achieving the goal of treatment. However, inherent difficulties in designing experimental trials have left much of TCM yet to be substantiated by science. Despite that, TCM not only remains a popular form of medical treatment among the Chinese, but is also gaining popularity in the West. This phenomenon has brought along with it increasing reports on herb-drug interactions, beckoning the attention of Western physicians, who will find it increasingly difficult to ignore the impact of TCM on Western therapies. This paper aims to facilitate the education of Western physicians on common Chinese herbs and raise awareness about potential interactions between these herbs and warfarin, a drug that is especially susceptible to herb-drug interactions due to its narrow therapeutic range.
\end{abstract}

Keywords: drugs, herbs, interaction, traditional Chinese medicine, warfarin

\section{INTRODUCTION}

Warfarin is an anticoagulant that is widely prescribed for chronic atrial fibrillation, mechanical valves, deep vein thrombosis and recurrent stroke. ${ }^{(1,2)}$ Patients on warfarin are often maintained on long-term therapy; hence, a substantial number turn concurrently to traditional Chinese medicine (TCM) for synergistic effects. This, coupled with the narrow therapeutic range of warfarin, renders these patients particularly susceptible to adverse outcomes from herb-warfarin interactions. Patients on warfarin are regularly monitored using the international normalised ratio (INR), of which a target between 2.0 and 3.5 is desired, depending on its indications. While the role of dietary changes in causing INR fluctuations is often discussed, little attention has been paid to the role of herbal medicines in altering the effects of warfarin.

The problem of herb-drug interaction is one that is pertinent. Firstly, TCM use is prevalent. A survey of a Singapore housing estate in 2005 showed that $76 \%$ used complementary medicine over the past year, of which TCM was the most common. ${ }^{(3)}$ Secondly, a significant proportion, estimated at $26.0 \%$ and $23.5 \%$ in Hong Kong and Italy, respectively, co-ingest warfarin and Chinese herbs. ${ }^{(4,5)}$ Thirdly, there is widespread undisclosed use of complementary medicine among Western doctors, which studies in Singapore and Italy have estimated at rates of $75.4 \%$ to more than $90.0 \%{ }^{(3,4)}$ Therefore, there is a need for practitioners to recognise the need to actively elicit the use of complementary medications from patients. This is especially important as most over-the-counter herbs, ${ }^{(3)}$ the commonest mode of complementary medicine use, do not contain key safety messages, such as that of herbal interaction with Western medications. ${ }^{(6)}$

Warfarin works by inhibiting vitamin $\mathrm{K}$ epoxide reductase, preventing the recycling of vitamin $\mathrm{K}$, which is needed to activate clotting factors II, VII, IX and X. These clotting factors are required for the formation of fibrin. ${ }^{(1,2)}$ Warfarin is orally administered in the form of R- and S-warfarin, of which S-warfarin is 3-5 times more active than R-warfarin. S-warfarin is mainly metabolised by CYP2C9; other enzymes include CYP2C8, CYP2C18 and CYP2C19. R-warfarin is mainly metabolised by CYP1A2 and CYP3A4; other enzymes include CYP1A1, CYP2C8, CYP2C18, CYP2C19 and CYP3A5. ${ }^{(2)}$

Interaction between warfarin and Chinese herbs can be classified into pharmacokinetic or pharmacodynamic interactions. Pharmacokinetic interactions affect the absorption, distribution, metabolism or elimination of a drug. Pharmacodynamic interactions result from synergistic or antagonistic effects of herbs on drugs. ${ }^{(7)}$ This paper aims to consolidate the available literature for and against the interactions between commonly used Chinese herbs and warfarin. This can, firstly, serve as a resource to help guide medical practitioners in counselling patients on the use of warfarin, and secondly, identify gaps in existing evidence.

\section{METHODS}

A recently published review article ${ }^{(8)}$ was consulted for a list of Chinese herbs with known or potential interaction with antiplatelets or anticoagulants, with the addition of other herbs known in TCM to invigorate blood circulation and stop bleeding. Of these, 44 Chinese herbs and supplements commonly used in Singapore were included in our study. A search was conducted in both English (PubMed) and Chinese (Wanfang Med Online) databases. Wanfang Med online is an established database that displays selected top Chinese medical journals in China. The $\mathrm{MeSH}$ headings and keywords were: warfarin or antiplatelet or anticoagulant or cytochrome P450, and the English, Chinese or Latin names of each Chinese herb. Bibliographies of the papers were also referred to for other relevant studies. All studies with relevant titles were retrieved and selected based on their abstracts. In view of the limited research papers in this area, all forms of

${ }^{1}$ Yong Loo Lin School of Medicine, ${ }^{2}$ Eu Yan Sang Integrative Health Pte Ltd, ${ }^{3}$ Medical Oncology, Parkway Cancer Centre, Singapore

Correspondence: Dr Khoo Kei Siong, Deputy Medical Director \& Senior Consultant, Medical Oncology, Parkway Cancer Centre, 6A Napier Road, Gleneagles Hospital \#01-35, Singapore 258500.khooks@pcc.sg 
publications, including randomised controlled trials, crossover studies, case reports, animal studies and in vitro studies, were selected. Studies involving herbal formulae were excluded. Studies over a 30-year period from 1983 to 2014 were included. Only articles involving warfarin were selected, with the exception of herbs that yielded no articles on interaction with warfarin. In such cases, interaction of the herb with other antiplatelets or anticoagulants was included in view of possible extrapolations, and such cases were highlighted.

Articles were selected independently by two authors based on title and abstract. The selected articles were approved by the two senior authors (an experienced TCM physician and an established Western physician with special interest in TCM) before the results were consolidated. The articles were analysed and the data was organised into an excel document for easy reference. Relevant data extracted included the study methodology, evidence and mechanism of interaction, and other information such as plant parts as well as herb and warfarin dosages, if available. The results were continually reviewed by the two senior authors and two other non-authors (an established Western practitioner and a senior Chinese physician) during meetings.

A total of 107 articles were selected based on title and abstract. Of these, only articles with full texts available were selected. A total of 77 articles were included: 13 case reports, 14 human studies, 21 animal studies and 29 in vitro studies. Of the human studies, two were randomised controlled studies and six were crossover studies. Given the limited number of randomised controlled studies available in this area, other articles (case reports, human studies, animal studies and in vitro studies) had to be included in the data analysis. The type of study from which each piece of evidence was obtained was included in the collated table of results for the reader's reference.

\section{RESULTS}

The information gathered from the search has been classified into four tables for easy reference. Table I contains the existing evidence and mechanism of herb-warfarin interactions of herbs with the greatest evidence of interaction with warfarin, ordered based on decreasing evidence. Table II describes other herbwarfarin interactions based solely on experimental studies. Table III lists other common Chinese herbs with no published studies on their interaction with Warfarin. Table IV contains common indications of the 11 herbs found to have the greatest evidence of interaction with warfarin.

\section{DISCUSSION}

This review has evaluated the current published evidence regarding the herb-warfarin interactions of 44 commonly used Chinese herbal products in Singapore. Of these, 11 herbs (danshen, ginkgo, dong quai, American ginseng, safflower, peach kernel, licorice, Asian ginseng, lycium, ginger and notoginseng) were found to have the strongest evidence of potential interaction with warfarin. Expounded below is a discussion of published studies regarding the interactions of the aforementioned herbs as well as the evidence of their interactions with warfarin. Refer to the appendix for further information regarding the proposed mechanism of herb-warfarin interactions.

\section{Danshen 丹参 (Salvia miltiorrhiza Bge.)}

Published case reports have pointed to over-anticoagulation associated with concomitant danshen and warfarin use. . $^{(9,10)}$ A 62-year-old man developed haemothorax two weeks after daily consumption of a danshen decoction (INR > 8.4). Dechallenge of danshen with reintroduction of warfarin at original dosage returned his INR to therapeutic range. ${ }^{(9)}$ In addition, a controlled clinical trial $(\mathrm{n}=40)$ concluded that concomitant administration of two weeks of danshen with warfarin significantly prolonged prothrombin time (PT) and INR, as compared to those in the control group. ${ }^{(11)}$

\section{Ginkgo 银杏, 白果 (Ginkgo biloba L.)}

Numerous case reports of spontaneous bleeding with warfarin have been published. From 1966 to October 2004, 15 case reports were published describing the temporal association of ginkgo with bleeding. ${ }^{(12)}$ There was a single case report of a 78-year-old patient on warfarin who, following ginkgo consumption, developed intracerebral bleeding, which stopped with the discontinuation of ginkgo. ${ }^{(13)}$

However, clinical trials conducted have not substantiated these reports. A randomised, double-blind, placebo-crossover trial $(n=24)$ of patients who were stable on warfarin concluded that consumption of daily Ginkgo biloba $100 \mathrm{mg}$ for four weeks had no significant influence on warfarin response. ${ }^{(14)}$ Similarly, an open-label crossover study $(n=12)$ concluded that ginkgo at recommended doses did not significantly affect the pharmacokinetics or pharmacodynamics of a single $25 \mathrm{mg}$ dose of warfarin in healthy subjects. ${ }^{(15)}$

\section{Dong quai 当归 (Angelica sinensis [Oliv] Diel)}

A case report illustrated a 46-year-old woman on warfarin $5 \mathrm{mg} /$ day who developed two episodes of raised INR of 4.05 and 4.90, related to oral dong quai administration of $565 \mathrm{mg} 1-2$ times daily. A month after dong quai was discontinued, with warfarin dose maintained, her INR dropped to 2.48. ${ }^{(16)}$

\section{American ginseng 西洋参 (Panax quinquefolius L.)}

A randomised, double-blind, placebo-controlled trial of healthy patients $(n=20)$ concluded that two weeks of American ginseng $1.0 \mathrm{~g}$ twice daily significantly reduced peak INR, peak plasma warfarin and warfarin area under the curve. ${ }^{(17)}$ However, experimental studies have yielded conflicting results. A study by Li et al found that Panax quinquefolius significantly extended activated partial thromboplastin time, PT and thrombin time in human plasma in vitro. ${ }^{(18)}$

\section{Safflower 红花 (Carthamus tinctorius L.)}

A case report depicted bleeding and raised INR associated with safflower use. ${ }^{(33)}$ A 74-year-old man on warfarin $1.25 \mathrm{mg} /$ day with therapeutic INR developed haematuria after 14 days of consumption of safflower $20 \mathrm{~g}$ (INR 5.31). When he was subsequently restarted on the same dose of warfarin 
Table I. Summary of existing evidence of the interaction between warfarin and Chinese herbal medicines.

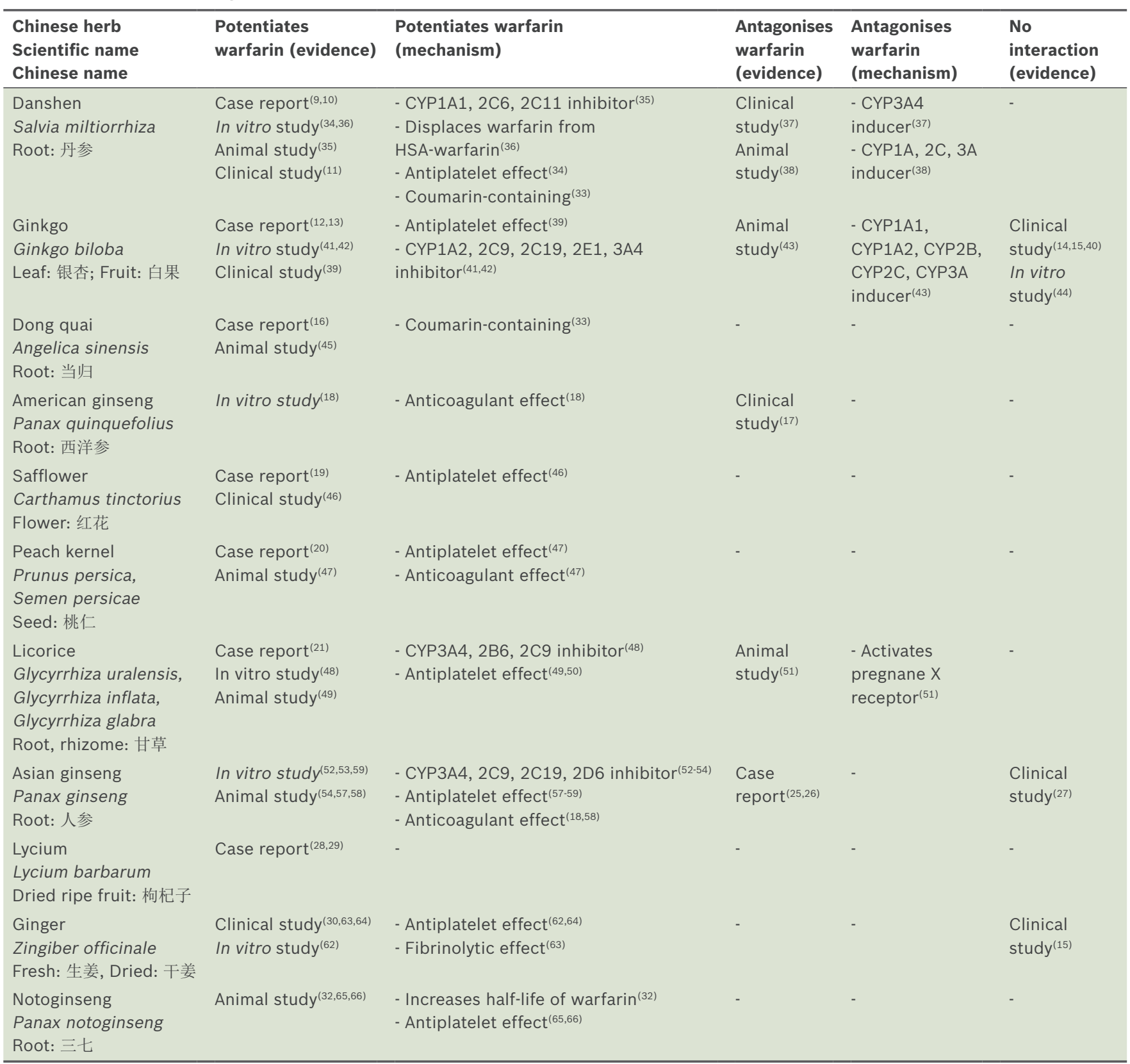

HSA: human serum albumin

without safflower use, his INR dropped to 1.64-2.57. However, it was highlighted that at $20 \mathrm{~g}$, the patient had exceeded the recommended safflower daily dosage of $10 \mathrm{~g} .{ }^{(19)}$

\section{Peach kernel 桃仁 (Prunus persica [L.] Batsch, Semen persicae)}

A case report illustrated a 54-year-old woman on stable warfarin (INR 2.0-2.5) who experienced an isolated episode of INR at 5.5, related to daily consumption of peach kernel. Dechallenge of peach kernel with original warfarin dose resulted in normalisation of INR to 2.1. ${ }^{(20)}$

\section{Licorice 甘草 (Glycyrrhiza uralensis Fisch., Glycyrrhiza inflata Bat., Glycyrrhiza glabra L.)}

A case report described an 80-year-old woman on stable warfarin who developed two episodes of melaena (INR 9.1 and 5.5) associated with ingestion of a pound of black licorice. ${ }^{(21)}$ After dechallenge of licorice, her INR normalised to 1.2 two weeks later.

\section{Asian ginseng 人参 (Panax ginseng)}

The effect of ginseng on warfarin has not been established due to abundant conflicting results. Ginseng has been associated with a few episodes of spontaneous bleeding, ${ }^{(22-24)}$ but have also been associated with reports of subtherapeutic INR and thrombosis in patients previously stable on warfarin. ${ }^{(25,26)}$

The effect of ginseng on warfarin has not been replicated in clinical trials. A randomised, open-label, controlled study of newly diagnosed ischaemic stroke patients $(n=35)$ found that two weeks of concomitant use of Panax ginseng extract $1.5 \mathrm{~g}$ with warfarin did not significantly affect peak values, INR and PT area under the curve, thus concluding that Panax ginseng did not influence the pharmacological action of warfarin. ${ }^{(27)}$ 
Table II. Proposed mechanism of interaction between warfarin and other Chinese herbal medicines.

\begin{tabular}{|c|c|c|c|}
\hline Mechanism & Herb & Scientific name & Chinese name \\
\hline \multirow{9}{*}{$\begin{array}{l}\text { Pharmacodynamic } \\
\text { interaction via } \\
\text { antiplatelet } \\
\text { effects }\end{array}$} & Motherwort ${ }^{(67)}$ & Leonurus japonicus & 益母草, Seed: 莣蔚子 \\
\hline & Danshen $^{(68)}$ & $\begin{array}{l}\text { Codonopsis pilosula, Codonopsis pilosula, } \\
\text { Codonopsis tangshen }\end{array}$ & Root: 党参 \\
\hline & Reishi/Lingzhi $(69,70)$ & Ganoderma lucidum & Sporophore: 灵芝 \\
\hline & Dandelion $^{(71)}$ & $\begin{array}{l}\text { Taraxacum mongolicum, Taraxacum sinicum, } \\
\text { Taraxacum officinale }\end{array}$ & Whole plant: 蒲公英 \\
\hline & Cassia(72) & Cassia obtusifolia, Cassia tora & Dried ripe seed: 决明子 \\
\hline & Burdock ${ }^{(73)}$ & Arctium lappa & Ripe fruit: 牛蒡子 \\
\hline & Coltsfoot $^{(74)}$ & Tussilago farfara & Flower: 款冬花 \\
\hline & Hawthorn ${ }^{(75)}$ & Crateagus pinnatifida & Fruit: 山楂 \\
\hline & Turmeric $^{(76)}$ & Curcuma longa & Rhizome: 姜黄 \\
\hline \multirow{8}{*}{$\begin{array}{l}\text { Pharmacokinetic } \\
\text { interaction via } \\
\text { CYP450 inhibition }\end{array}$} & Astragalus(77) & $\begin{array}{l}\text { Astragalus membranaceus, Astragalus } \\
\text { membranaceus }\end{array}$ & Root: 黄芪 \\
\hline & Bitter orange/sour orange ${ }^{(78,79)}$ & Citrus aurantium, Citrus sinensis & $\begin{array}{l}\text { Unripe fruit: 枳实; } \\
\text { Ripe fruit peel: 枳壳 }\end{array}$ \\
\hline & Skullcap ${ }^{(77)}$ & Scutellaria baicalensis & Root: 黄芩 \\
\hline & Coptis Rhizome ${ }^{(80)}$ & Coptis chinensis, Coptis deltoidea, Coptis teeta & 黄连 \\
\hline & Cat's claw ${ }^{(81)}$ & Ranunculus ternatus, Uncaria tomentosa & Tuberous root: 猫爪草 \\
\hline & Angelica(82) & Angelica dahurica & Root:白芷 \\
\hline & Notopterygium root ${ }^{(82)}$ & Notopterygium incisum, Notopterygium forbesii & 㒸活 \\
\hline & Saposhnikovia $\operatorname{root}^{(82)}$ & Saposhnikovia divaricata & 防风 \\
\hline \multirow{3}{*}{$\begin{array}{l}\text { Antiplatelet } \\
\text { effects + CYP450 } \\
\text { inhibition }\end{array}$} & Peony $(77,83,84)$ & Paeonia suffruticosa, Paeonia lactiflora & $\begin{array}{l}\text { Root cortex: 牡丹皮 } \\
\text { Root: 药药, 赤苻, 白苻 }\end{array}$ \\
\hline & Pubescent angelica ${ }^{(82,85)}$ & Angelica pubescens & Root: 独活 \\
\hline & Andrographis ${ }^{(86-90)}$ & Andrographis paniculata & Whole plant: 穿心莲 \\
\hline
\end{tabular}

Table III. Chinese herbs (scientific and Chinese names) with no evidence of interaction with warfarin.

\begin{tabular}{|c|c|c|}
\hline Chinese Herb & Scientific name & Chinese name \\
\hline Corydalis yanhusuo & Corydalis yanhusuo & Tuber: 延胡索 \\
\hline Glehnia & Glehnia littoralis & Root: 北沙参 \\
\hline Chrysanthemum & Chrysanthemum morifolium & Flower: 菊花 \\
\hline Siberian cork-tree bark & Phellodendron chinense & 黄柏 \\
\hline Schisandra fruit & Schisandra chinesis & 五味子 \\
\hline Kelp & Sargassum pallidum, Sargassum fusiforme & Frond: 海藻 \\
\hline Da huang & Rheum palmatum, Rheum tanguticum, Rheum officinale & Root and tuber: 大黄 \\
\hline Magnolia bark & Magnolia officinalis, Magnolia officinalis & Bark: 厚朴 \\
\hline Plantain & Plantago asiatica, Plantago depressa & Seed: 车前子 Whole plant: 车前草 \\
\hline Rhodiola & Rhodiola rosea, Rhodiola euryphylla & Rhizome: 红景天 \\
\hline
\end{tabular}

\section{Lycium 构杞子 (Lycium barbarum L.)}

There has been evidence of potentiation of warfarin linked to the consumption of this Chinese herb, as published in case reports of raised INR and bleeding associated with concomitant use of warfarin and lycium. A 71-year-old woman developed epistaxis, ecchymosis and haematochezia (INR of indeterminate level) ${ }^{(28)}$ and an 80-year-old woman on warfarin (weekly dosage 15.5-16.5 mg) with therapeutic INR developed two episodes of raised INR (4.97 and 3.86) associated with the consumption of concentrated herbal tea containing Lycium barbarum (estimated dosage 20-40 g/day) for 1-2 days prior to blood-taking. ${ }^{(29)}$ Avoidance of the herbal tea returned INR to therapeutic range.

\section{Ginger 生姜, 干姜 (Zingiber officinale Rosc.)}

A prospective longitudinal study of patients on warfarin $(n=171)$ found that ginger was independently associated with increased risk of self-reported bleeding. ${ }^{(30)}$ Although studies on interaction between ginger and warfarin were not found, a case report illustrated an over-anticoagulatory effect of ginger on phenprocoumon, a coumarin derivative. ${ }^{(31)} \mathrm{A}$ 76-year-old woman on long-term phenprocoumon with stable INR within therapeutic 
Table IV. Common traditional Chinese medicine (TCM) uses of the Chinese herbs with the greatest evidence of interaction with warfarin.

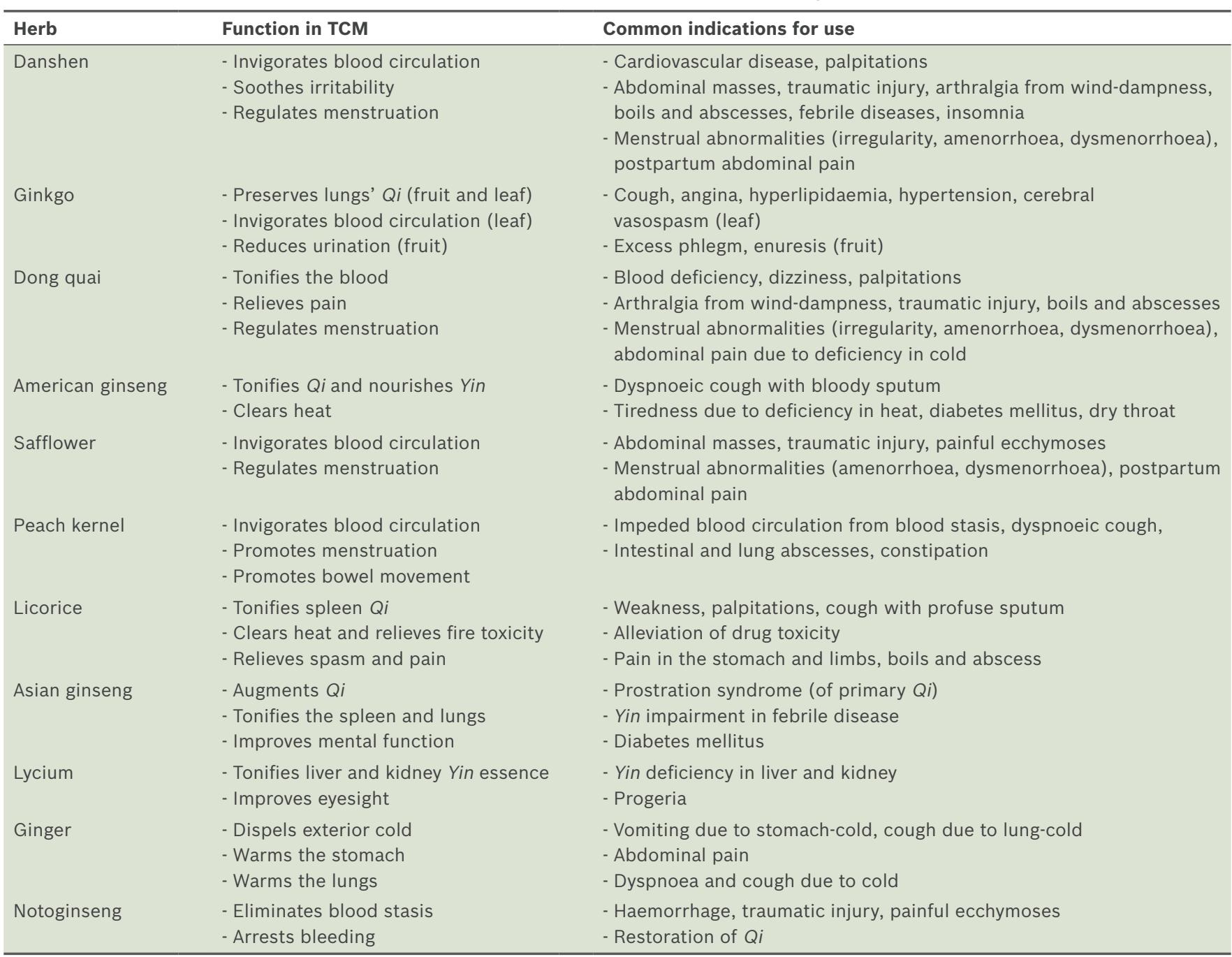

range developed epistaxis (INR > 10), related to several weeks of regular ginger intake in the form of dried ginger and tea from ginger powder. Discontinuation of ginger and resumption of phenprocoumon at previous dose returned INR to therapeutic range. The Naranjo probability scale scored ginger as a probable cause of the over-anticoagulation.

\section{Notoginseng 三七 (Panax notoginseng [Burk.])}

Clinical studies or case reports on interaction between Notoginseng and warfarin were not located. However, experimental studies conducted in rats found that administration of notoginseng $20 \mathrm{mg} / \mathrm{kg} /$ day for five weeks increased the $T_{\text {max }}$ half-life and area under the curve of warfarin. ${ }^{(32)}$

It is acknowledged that this review has some limitations. Firstly, the use of only two databases may have limited the papers retrieved; however, both selected databases are established ones, with PubMed displaying over 25,000 journals and Wanfang, about 200 selected Chinese medical journals. Secondly, the list of 40 potential herb-warfarin interactions is not exhaustive. Also, data processing was complicated by the exclusion of scientific names of herbs in some published papers; thus, discretion had to be exercised in such cases. Another limitation stems from the common prescription of Chinese herbs in formulas, which renders this combinatory effect of multiple Chinese herbs on warfarin difficult to address due to the customisation of prescribed formulas, and thus, this has not been explored in our paper. Notably, there was a paucity of high-level evidence (such as meta-analyses and randomised controlled trials) in this area of research. The deliberate inclusion of in vitro studies, animal studies and case reports in this review article was made in an attempt to elucidate the possible interactions with warfarin in vivo. Finally, conflicting results of herb-warfarin interaction further complicated the review of data. For instance, in the case of danshen, while some case reports, animal studies and in vitro studies have suggested a possible potentiation effect, other clinical studies and animal studies have suggested a possible antagonistic effect between the two instead. As such, we recommend that more high-quality studies (i.e. randomised controlled trials) be conducted and that more case reports be documented regarding herb-warfarin interaction.

\section{CONCLUSION AND RECOMMENDATIONS FOR PRACTICE}

This review article has identified the possible effects of 44 commonly consumed TCM herbs and supplements on warfarin, and provided recommendations with regard to concomitant ingestion with warfarin. We strongly encourage 
the cooperation of both Western doctors and Chinese physicians in ensuring safety in patients on warfarin. Western doctors are advised to regularly screen for TCM use, especially in patients with indications as listed in Table IV, and to advise against the use of herbs that interact with warfarin. Chinese physicians, likewise, are advised to screen for warfarin use in their patients and to adjust their choice of herbs accordingly.

Many of the interactions of herbs with warfarin are extrapolated from experimental studies; the in vivo effects on humans, however, remain to be found. We also acknowledge that many other herb-warfarin interactions likely go unrecognised by unsuspecting practitioners. As such, we advise that practitioners be cognisant of the entity of herb-warfarin interactions and maintain a high index of suspicion in patients with poor INR control. In view of the documented reports and studies highlighting the risk of over- or under-anticoagulation of the 11 herbs (i.e. danshen, ginkgo, dong quai, American ginseng, safflower, peach kernel, licorice, Asian ginseng, lycium, ginger and notoginseng) with warfarin, we opine that it would only be prudent to exercise caution in cases of concomitant use of these herbs with warfarin.

Despite their vast differences, both Western and Chinese medicines are employed with the similar goal of optimising patient outcomes. It is our belief that in the near future, with the aid of further studies dedicated to the advancement of knowledge in this area, close cooperation between Western and Chinese physicians will allow for Chinese herbs and Western medicines to be concomitantly prescribed for synergistic effects.

\section{ACKNOWLEDGEMENTS}

We would like to thank Associate Professor Lau Tang Ching, Senior Consultant, National University Hospital, Singapore, and Physician He Qiu Ling, Senior Physician, Eu Yan Sang Integrative Health Pte Ltd, Singapore, for their comments and suggestions, and Miss Eva Shen for her administrative support.

\section{REFERENCES}

1. Piatkov I, Rochester C, Jones $T$, Boyages $S$. Warfarin toxicity and individual variability-clinical case. Toxins (Basel) 2010; 2:2584-92.

2. Wadelius $M$, Chen LY, Eriksson N, et al. Association of warfarin dose with genes involved in its action and metabolism. Hum Genet 2007; 121:23-34.

3. Lim MK, Sadarangani P, Chan HL, Heng JY. Complementary and alternative medicine use in multiracial Singapore. Complement Ther Med 2005; 13:16-24.

4. Cuzzolin L, Francini-Pesenti F, Zaffani S, et al. Knowledges about herbal products among subjects on warfarin therapy and patient-physician relationship: a pilot study. Pharmacoepidemiol Drug Saf 2007; 16:1014-7.

5. Wong RS, Cheng G, Chan TY. Use of herbal medicines by patients receiving warfarin. Drug Saf 2003; 26:585-8.

6. Raynor DK, Dickinson R, Knapp P, Long AF, Nicolson DJ. Buyer beware? Does the information provided with herbal products available over the counter enable safe use? BMC Med 2011; 9:94.

7. Yap KY, See CS, Chan A. Clinically-relevant chemotherapy interactions with complementary and alternative medicines in patients with cancer. Recent Pat Food Nutr Agric 2010; 2:12-55.

8. Tsai HH, Lin HW, Lu YH, Chen YL, Mahady GB. A review of potential harmful interactions between anticoagulant/antiplatelet agents and Chinese herbal medicines. PLoS One 2013; 8:e64255.

9. Izzat MB, Yim AP, El-Zufari MH. A taste of Chinese medicine! Ann Thorac Surg 1998; 66:941-2.

10. Yu CM, Chan JC, Sanderson JE. Chinese herbs and warfarin potentiation by 'danshen'. J Intern Med 1997; 241:337-9.

11. Qing Y, Jin-qi J. [Effect of danshen tablet on the anticoagulation of warfarin]. Chinese Traditional Patent Medicine 2008; 30:19-21. Chinese.
12. Bent S, Goldberg H, Padula A, Avins AL. Spontaneous bleeding associated with ginkgo biloba: a case report and systematic review of the literature: a case report and systematic review of the literature. J Gen Intern Med 2005; 20:657-61.

13. Matthews MK Jr. Association of Ginkgo biloba with intracerebral hemorrhage. Neurology 1998; 50:1933-4.

14. Engelsen J, Nielsen JD, Winther K. Effect of coenzyme Q10 and Ginkgo biloba on warfarin dosage in stable, long-term warfarin treated outpatients. A randomised, double blind, placebo-crossover trial. Thromb Haemost 2002; 87:1075-6

15. Jiang $X$, Williams KM, Liauw WS, et al. Effect of ginkgo and ginger on the pharmacokinetics and pharmacodynamics of warfarin in healthy subjects. $\mathrm{Br}$ J Clin Pharmacol 2005; 59:425-32.

16. Page RL 2nd, Lawrence JD. Potentiation of warfarin by dong quai. Pharmacotherapy 1999; 19:870-6.

17. Yuan CS, Wei G, Dey L, et al. Brief communication: American ginseng reduces warfarin's effect in healthy patients: a randomized, controlled Trial. Ann Intern Med 2004; 141:23-7.

18. Li CT, Wang HB, Xu BJ. A comparative study on anticoagulant activities of three Chinese herbal medicines from the genus Panax and anticoagulant activities of ginsenosides Rg1 and Rg2. Pharm Biol 2013; 51:1077-80.

19. 张宇. 华法林联用红花水煎剂致泌尿系出血1例分析. J Changchun University Tradit Chin Med 2012; 28:466. Chinese.

20. 蓝宇, 于侯. 食用核桃仁增强华法林药效 1 例报道. Chin J Throm Hemos 2006; 12:125. Chinese.

21. Liu JF, Srivatsa A, Kaul V. Black licorice ingestion: Yet another confounding agent in patients with melena. World J Gastrointest Surg 2010; 2:30-1.

22. Greenspan EM. Ginseng and vaginal bleeding. JAMA 1983; 249:2018.

23. Hopkins MP, Androff L, Benninghoff AS. Ginseng face cream and unexplained vaginal bleeding. Am J Obstet Gynecol 1988; 159:1121-2.

24. Kabalak AA, Soyal OB, Urfalioglu A, Saracoglu F, Gogus N. Menometrorrhagia and tachyarrhythmia after using oral and topical ginseng. J Womens Health (Larchmt) 2004; 13:830-3.

25. 张彦丽等. 华法林与中草药的相互作用. 中国药物警 2011; 8:41-5. Chinese.

26. Rosado MF. Thrombosis of a prosthetic aortic valve disclosing a hazardous interaction between warfarin and a commercial ginseng product. Cardiology 2003; 99:111.

27. Lee SH, Ahn YM, Ahn SY, Doo HK, Lee BC. Interaction between warfarin and Panax ginseng in ischemic stroke patients. J Altem Complement Med 2008; 14:715-21

28. Rivera CA, Ferro CL, Bursua AJ, Gerber BS. Probable interaction between Lycium barbarum (goji) and warfarin. Pharmacotherapy 2012; 32:e50-3.

29. Leung H, Hung A, Hui AC, Chan TY. Warfarin overdose due to the possible effects of Lycium barbarum L. Food Chem Toxicol 2008; 46:1860-2.

30. Shalansky S, Lynd L, Richardson K, Ingaszewski A, Kerr C. Risk of warfarinrelated bleeding events and supratherapeutic international normalized ratios associated with complementary and alternative medicine: a longitudinal analysis. Pharmacotherapy 2007; 27:1237-47.

31. Krüth P, Brosi E, Fux R, Mörike K, Gleiter CH. Ginger-associated overanticoagulation by phenprocoumon. Ann Pharmacother 2004; 38:257-60.

32. 李晓宇等. 三七总㿝苷注射液对大鼠肝 CYP450 酶的影响. 中国临床药理学 与治疗学 2009; 14:849-54. Chinese.

33. Nutescu EA, Shapiro NL, Ibrahim S, West P. Warfarin and its interactions with foods, herbs and other dietary supplements. Expert Opin Drug Saf 2006; 5:433-51.

34. Wang Z, Roberts JM, Grant PG, Colman RW, Schreiber AD. The effect of a medicinal Chinese herb on platelet function. Thromb Haemost 1982; 48:301-6.

35. Wu WW, Yeung JH. Inhibition of warfarin hydroxylation by major tanshinones of Danshen (Salvia miltiorrhiza) in the rat in vitro and in vivo. Phytomedicine 2010; 17:219-26

36. Liu J, Wang X, Cai Z, Lee FS. Effect of tanshinone IIA on the noncovalent interaction between warfarin and human serum albumin studied by electrospray ionization mass spectrometry. J Am Soc Mass Spectrom 2008; 19:1568-75.

37. Qiu F, Wang G, Zhang R, et al. Effect of danshen extract on the activity of CYP3A4 in healthy volunteers. Br J Clin Pharmacol 2010; 69:656-62.

38. Kuo YH, Lin YL, Don MJ, Chen RM, Ueng YF. Induction of cytochrome P450-dependent monooxygenase by extracts of the medicinal herb Salvia miltiorrhiza. J Pharm Pharmacol 2006; 58:521-7.

39. Chung KF, Dent G, McCusker M, et al. Effect of a ginkgolide mixture (BN 52063) in antagonising skin and platelet responses to platelet activating factor in man. Lancet 1987; 1:248-51.

40. Kohler S, Funk P, Kieser M. Influence of a 7-day treatment with Ginkgo biloba special extract EGb 761 on bleeding time and coagulation: a randomized, placebo-controlled, double-blind study in healthy volunteers. Blood Coagul Fibrinolysis 2004; 15:303-9.

41. Zou L, Harkey MR, Henderson GL. Effects of herbal components on cDNAexpressed cytochrome P450 enzyme catalytic activity. Life Sci 2002; 71:1579-89. 
42. Gaudineau C, Beckerman R, Welbourn S, Auclair K. Inhibition of human P450 enzymes by multiple constituents of the Ginkgo biloba extract. Biochem Biophys Res Commun 2004; 318:1072-8.

43. Taki Y, Yokotani K, Yamada S, et al. Ginkgo biloba extract attenuates warfarin-mediated anticoagulation through induction of hepatic cytochrome P450 enzymes by bilobalide in mice. Phytomedicine 2012; 19:177-82.

44. Gurley BJ, Gardner SF, Hubbard MA, et al. Clinical assessment of effects of botanical supplementation on cytochrome P450 phenotypes in the elderly: St John's wort, garlic oil, Panax ginseng and Ginkgo biloba. Drugs Aging 2005; 22:525-39.

45. Lo AC, Chan K, Yeung JH, Woo KS. Danggui (Angelica sinensis) affects the pharmacodynamics but not the pharmacokinetics of warfarin in rabbits. Eur J Drug Metab Pharmacokinet 1995; 20:55-60.

46. Kwon JS, Snook JT, Wardlaw GM, Hwang DH. Effects of diets high in saturated fatty acids, canola oil, or safflower oil on platelet function, thromboxane B2 formation, and fatty acid composition of platelet phospholipids. Am J Clin Nutr 1991; 54:351-8.

47. Yang NY, Liu L, Tao WW, et al. Antithrombotic lipids from Semen Persicae. Nat Prod Res 2011; 25:1650-6.

48. Kent UM, Aviram M, Rosenblat M, Hollenberg PF. The licorice root derived isoflavan glabridin inhibits the activities of human cytochrome P450S 3A4, 2B6, and 2C9. Drug Metab Dispos 2002; 30:709-15

49. Francischetti IM, Monteiro RQ, Guimarães JA. Identification of glycyrrhizin as a thrombin inhibitor. Biochem Biophys Res Commun 1997; 235:259-63.

50. Tawata M, Yoda Y, Aida K, et al. Anti-platelet action of GU-7, a 3-arylcoumarin derivative, purified from glycyrrhizae radix. Planta Med 1990; 56:259-63.

51. Mu Y, Zhang J, Zhang S, et al. Traditional Chinese medicines Wu Wei Z (Schisandra chinensis Baill) and Gan Cao (Glycyrrhiza uralensis Fisch) activate pregnane $\mathrm{X}$ receptor and increase warfarin clearance in rats. J Pharmacol Exp Ther 2006; 316:1369-77.

52. Patel J, Buddha B, Dey S, Pal D, Mitra AK. In vitro interaction of the HIV protease inhibitor ritonavir with herbal constituents: changes in P-gp and CYP3A4 activity. Am J Ther 2004; 11:262-77.

53. Foster BC, Vandenhoek S, Tang R, et al. Effect of several Chinese natural health products of human cytochrome P450 metabolism. J Pharm Pharm Sci 2002 5:185-9.

54. Liu Y, Zhang JW, Li W, et al. Ginsenoside metabolites, rather than naturally occurring ginsenosides, lead to inhibition of human cytochrome P450 enzymes. Toxicol Sci 2006; 91:356-64

55. Jiang X, Blair EY, McLachlan AJ. Investigation of the effects of herbal medicines on warfarin response in healthy subjects: a population pharmacokinetic pharmacodynamic modeling approach. J Clin Pharmacol 2006; 46:1370-8.

56. Gurley BJ, Gardner SF, Hubbard MA, et al. Cytochrome P450 phenotypic ratios for predicting herb-drug interactions in humans. Clin Pharmacol Ther 2002; 72:276-87.

57. Kuo SC, Teng CM, Lee JC, et al. Antiplatelet components in Panax ginseng. Planta Med 1990; 56:164-7.

58. Park HJ, Lee JH, Song YB, Park KH. Effects of dietary supplementation of lipophilic fraction from Panax ginseng on CGMP and CAMP in rat platelets and on blood coagulation. Biol Pharm Bull 1996; 19:1434-9.

59. Park HJ, Rhee MH, Park KM, Nam KY, Park KH. Effect of non-saponin fraction from Panax ginseng on cGMP and thromboxane A2 in human platele aggregation. J Ethnopharmacol 1995; 49:157-62

60. Beckert BW, Concannon MJ, Henry SL, Smith DS, Puckett CL. The effect of herbal medicines on platelet function: an in vivo experiment and review of the literature. Plast Reconstr Surg 2007; 120:2044-50.

61. Lam AY, Elmer GW, Mohutsky MA. Possible interaction between warfarin and Lycium barbarum L. Ann Pharmacother 2001; 35:1199-201.

62. Srivastava KC. Aqueous extracts of onion, garlic and ginger inhibit platele aggregation and alter arachidonic acid metabolism. Biomed Biochim Acta 1984; 43:S335-46.

63. Verma SK, Bordia A. Ginger, fat and fibrinolysis. Indian J Med Sci 2001; 55:83-6.

64. Verma SK, Singh J, Khamesra R, Bordia A. Effect of ginger on platelet aggregation in man. Indian J Med Res 1993; 98:240-2.

65. Wang J, Huang ZG, Cao H, et al. Screening of anti-platelet aggregation agents from Panax notoginseng using human platelet extraction and HPLC-DAD-ESIMS/MS. J Sep Sci 2008; 31:1173-80.

66. Lau AJ, Toh DF, Chua TK, et al. Antiplatelet and anticoagulant effects of Panax notoginseng: comparison of raw and steamed Panax notoginseng with Panax ginseng and Panax quinquefolium. J Ethnopharmacol 2009; 125:380-6.

67. Xiong L, Zhou QM, Peng C, et al. Sesquiterpenoids from the herb of Leonurus japonicus. Molecules 2013; 18:5051-8.

68. Xu X, Wang SR, Lin Q. [Clinical and experimental study on codonopsis pilosula oral liquor in treating coronary heart disease with blood stasis]. Zhongguo Zhong Xi Yi Jie He Za Zhi 1995; 15:398-400. Chinese.

69. Kumaran S, Palani P, Nishanthi R, Kaviyarasan V. Studies on screening, isolation and purification of a fibrinolytic protease from an isolate (VK12) of Ganoderma lucidum and evaluation of its antithrombotic activity. Med Mycol J 2011; 52:153-62

70. Su C, Shiao M, Wang C. Potentiation of ganodermic acid S on prostaglandin E(1)-induced cyclic AMP elevation in human platelets. Thromb Res 2000; 99:135-45.

71. Schütz K, Carle R, Schieber A. Taraxacum--a review on its phytochemical and pharmacological profile. J Ethnopharmacol 2006; 107:313-23.

72. Yun-Choi HS, Kim JH, Takido M. Potential inhibitors of platelet aggregation from plant sources, V. Anthraquinones from seeds of Cassia obtusifolia and related compounds. J Nat Prod 1990; 53:630-3.

73. Iwakami S, Wu JB, Ebizuka Y, Sankawa U. Platelet activating factor (PAF) antagonists contained in medicinal plants: lignans and sesquiterpenes. Chem Pharm Bull (Tokyo) 1992; 40:1196-8.

74. Hwang SB, Chang MN, Garcia ML, et al. L-652,469--a dual receptor antagonist of platelet activating factor and dihydropyridines from Tussilago farfara L. Eur J Pharmacol 1987; 141:269-81.

75. Vibes J, Lasserre B, Gleye J, Declume C. Inhibition of thromboxane A2 biosynthesis in vitro by the main components of Crataegus oxyacantha (Hawthorn) flower heads. Prostaglandins Leukot Essent Fatty Acids 1994; 50:173-5.

76. Lee HS. Antiplatelet property of Curcuma longa L. rhizome-derived ar-turmerone. Bioresour Technol 2006; 97:1372-6.

77. Pao LH, Hu OY, Fan HY, et al. Herb-drug interaction of 50 Chinese herbal medicines on CYP3A4 activity in vitro and in vivo. Am J Chin Med 2012; 40:57-73.

78. Edwards DJ, Fitzsimmons ME, Schuetz EG, et al. 6', 7'-Dihydroxybergamottin in grapefruit juice and Seville orange juice: effects on cyclosporine disposition, enterocyte CYP3A4, and P-glycoprotein. Clin Pharmacol Ther 1999; 65:237-44.

79. Malhotra S, Bailey DG, Paine MF, Watkins PB. Seville orange juice-felodipine interaction: comparison with dilute grapefruit juice and involvement of furocoumarins. Clin Pharmacol Ther 2001; 69:14-23.

80. Han YL, Yu HL, Li D, et al. In vitro inhibition of Huanglian [Rhizoma coptidis (L.)] and its six active alkaloids on six cytochrome P450 isoforms in human liver microsomes. Phytother Res 2011; 25:1660-5.

81. Budzinski JW, Foster BC, Vandenhoek S, Arnason JT. An in vitro evaluation of human cytochrome P450 3A4 inhibition by selected commercial herbal extracts and tinctures. Phytomedicine 2000; 7:273-82

82. Guo LQ, Taniguchi M, Chen QY, Baba K, Yamazoe Y. Inhibitory potential of herbal medicines on human cytochrome P450-mediated oxidation: properties of umbelliferous or citrus crude drugs and their relative prescriptions. Jpn J Pharmacol 2001; 85:399-408.

83. Wong AL, Chan TY. Interaction between warfarin and the herbal product quilinggao. Ann Pharmacother 2003; 37:836-8

84. Koo YK, Kim JM, Koo JY, et al. Platelet anti-aggregatory and blood anticoagulant effects of compounds isolated from Paeonia lactiflora and Paeonia suffruticosa. Pharmazie 2010; 65:624-8.

85. Ko FN, Wu TS, Liou MJ, Huang TF, Teng CM. Inhibition of platelet thromboxane formation and phosphoinositides breakdown by osthole from Angelica pubescens. Thromb Haemost 1989; 62:996-9.

86. Amroyan E, Gabrielian E, Panossian A, Wikman G, Wagner H. Inhibitory effect of andrographolide from Andrographis paniculata on PAF-induced platelet aggregation. Phytomedicine 1999; 6:27-31.

87. Lu WJ, Lee JJ, Chou DS, et al. A novel role of andrographolide, an NFkappa B inhibitor, on inhibition of platelet activation: the pivotal mechanisms of endothelial nitric oxide synthase/cyclic GMP. J Mol Med (Berl) 2011; 89:1261-73

88. Ooi JP, Kuroyanagi M, Sulaiman SF, Muhammad TS, Tan ML. Andrographolide and 14-deoxy-11, 12-didehydroandrographolide inhibit cytochrome P450s in HepG2 hepatoma cells. Life Sci 2011; 88:447-54

89. Pan $Y$, Abd-Rashid BA, Ismail $Z$, et al. In vitro determination of the effect of Andrographis paniculata extracts and andrographolide on human hepatic cytochrome P450 activities. I Nat Med 2011; 65:440-7.

90. Thisoda P, Rangkadilok N, Pholphana N, et al. Inhibitory effect of Andrographis paniculata extract and its active diterpenoids on platelet aggregation. Eur J Pharmacol 2006; 553:39-45.

91. Choo MK, Park EK, Yoon HK, Kim DH. Antithrombotic and antiallergic activities of daidzein, a metabolite of puerarin and daidzin produced by human intestinal microflora. Biol Pharm Bull 2002; 25:1328-32.

92. Guerra MC, Speroni E, Broccoli M, et al. Comparison between chinese medical herb Pueraria lobata crude extract and its main isoflavone puerarin antioxidant properties and effects on rat liver CYP-catalysed drug metabolism. Life Sci 2000; 67:2997-3006.

93. Liu R, Xing D, Lu H, Wu H, Du L. Pharmacokinetics of puerarin and ginsenoside $\mathrm{Rg} 1$ of $\mathrm{CBN}$ injection and the relation with platelet aggregation in rats. Am J Chin Med 2006; 34:1037-45.

94. Yu Z, Zhang G, Zhao H. [Effects of Puerariae isoflavone on blood viscosity, thrombosis and platelet function]. Zhong Yao Cai 1997; 20:468-9. Chinese. 


\title{
Appendix
}

\author{
Mechanism of interaction: danshen on warfarin \\ Pharmacodynamic: Danshen contains coumarin derivatives, ${ }^{(33)}$ and has been found to exhibit antiplatelet effects by inhibiting platelet aggregation \\ using platelet CAMP. ${ }^{(34)}$ \\ Pharmacokinetic: In vitro studies have found that tanshinones in danshen inhibit CYP1A1, 2C6 and 2C11-mediated warfarin metabolism, and \\ that sodium tanshinone IIA sulfonate replaces warfarin from the binding site on human serum albumin-warfarin complex, increasing free warfarin \\ concentration in blood. ${ }^{(35,36)}$ However, in vivo and ex vivo studies have found that danshen components induce CYP3A4 in humans, and CYP1A, \\ $2 \mathrm{C}$ and $3 \mathrm{~A}$ in mice. ${ }^{(37,38)}$
}

Mechanism of interaction: ginkgo on warfarin

Pharmacodynamic: In a crossover study $(\mathrm{n}=6)$, BN52063 in ginkgo was found to inhibit platelet-activating factor-induced platelet aggregation. $\left.{ }^{39}\right)$ However, another crossover trial $(n=50)$ found no effect of EGb761 on platelet aggregation or blood coagulation, and no relationship between EGb761 and haemorrhagic complications. ${ }^{(40)}$

Pharmacokinetic: In vitro studies with human microsomes and animal studies found that Ginkgo biloba extract and active components (flavonoidic and terpenoidic fractions of EGb761) significantly inhibit CYP1A2, 2E1, 2C9, 3A4, 2C19, which may interfere with metabolism of warfarin. ${ }^{(41,42)}$ However, other studies have yielded conflicting results. An animal (mice) study concluded that warfarin anticoagulation effects were significantly attenuated by Ginkgo biloba extract and bilobalide, which decreased the concentration of R-warfarin by inducing CYP1A1, 1A2, 2B, 2C and 3A. ${ }^{(4)}$ In elderly volunteers, ginkgo had no effect on CYP3A4, 2D6, 2 E1 and 1A2 when midazolam, debrisoquine, chlorzoxazone and caffeine were used as probes. ${ }^{(44)}$

\section{Mechanism of interaction: dong quai on warfarin}

Pharmacodynamic: Dong quai contains coumarin constituents (ferulic acid, osthole) which have been shown to inhibit platelet aggregation. ${ }^{(33}$ Animal steady state studies have found that Dong quai significantly increased $\mathrm{PT}^{(45)}$ without any effect on warfarin concentration, suggesting the presence of pharmacodynamics, but not pharmacokinetic interactions.

\section{Mechanism of interaction: safflower on warfarin}

Pharmacodynamic: A clinical study of healthy volunteers $(n=30)$ found that 3 weeks of safflower oil and canola oil diets significantly reduced platelet aggregation. ${ }^{(46)}$

\section{Mechanism of interaction: peach kernel on warfarin}

Pharmacodynamic: Animal studies have found that peach kernel has antiplatelet and anticoagulation effects. Ethanol extract inhibits platelet aggregation, and petroleum ether extract prolongs thrombin time. ${ }^{(47)}$

\section{Mechanism of interaction: licorice on warfarin}

Pharmacokinetic: the supratherapeutic effects of licorice on warfarin can be explained by experimental studies, which showed pharmacokinetic inhibition of CYP3A4, 2B6, 2C9 of glabridin. ${ }^{(48)}$

Pharmacodynamic: Licorice components, glycyrrhizin and GU-7, have been found to exhibit antiplatelet activity in rabbit and human in vitro studies. ${ }^{(49,50)}$ However, in experimental rat studies, licorice has been found to activate pregnane X receptor in vitro and increase warfarin metabolism in vivo. If these results are extrapolated, licorice may reduce the antithrombotic effect of warfarin. ${ }^{(51)}$

\section{Mechanism of interaction: Asian ginseng on warfarin}

Pharmacokinetic: In vitro studies (human) have found that ginseng extract, constituents (kaempferol) and metabolites (compound K, protopanaxadoil, protopanaxatriol) inhibit CYP450 enzymes (CYP3A4, 2C9, 2C19, 2D6), which are involved in the metabolism of warfarin. ${ }^{(52-54)}$ However, a randomised crossover study of healthy volunteers $(n=24)$ found that Panax ginseng had a nonclinically significant effect on the clearance of warfarin. ${ }^{(55)}$ Also, 28 days of Panax ginseng (1,500 mg/day) use in both young (mean age 25 years) and elderly (mean age 67 years) healthy volunteers had no effect on CYP3A4, 2E1 and 1A2 activities. Although CYP2D6 was significantly inhibited by Panax ginseng in the elderly, the magnitude of the effect was not clinically significant. ${ }^{(44,56)}$

Pharmacodynamic: Antiplatelet and anticoagulant effects have also been described. In vitro studies (rabbit, rat, human) found that ginseng and its components (panaxynol, ginsenosides Ro, Rg1, Rg2, lipophilic fraction) inhibit platelet aggregation, possibly by regulating the levels of cGMP and TXA2, as well as inhibit release reaction and thromboxane formation. ${ }^{(57-59)}$ A recently published in vitro study found that Panax ginseng water extract $(0.05 \mathrm{mg} / \mathrm{mL}), \mathrm{Rg} 1$ and $\mathrm{Rg} 2$ significantly extended blood clotting time in human plasma as compared to that of the control group. ${ }^{(18)}$ However, a crossover trial of healthy adults $(n=10)$ found no significant alteration of platelet function after two weeks of ginseng consumption in recommended doses. ${ }^{(60)}$

\section{Mechanism of interaction: lycium on warfarin}

Pharmacokinetic: An in vitro study found that lycium weakly inhibits S-warfarin metabolism by CYP2C9, but the dissociation constant (Ki) value of $3.4 \mathrm{mg} / \mathrm{mL}$ suggests that other factors other than the CYP450 system may be responsible for the interaction. ${ }^{(61)}$

\section{Mechanism of interaction: ginger on warfarin}

Pharmacodynamic: Ginger (5 g dose) has been found in randomised placebo-controlled trials to inhibit platelet aggregation, possibly by inhibiting platelet COX products and thromboxane synthetase, and increase fibrinolytic activity ${ }^{(62-64)}$ However, an open-label, three-way crossover, randomised study $(n=12)$ found no evidence of pharmacodynamics or pharmacokinetic interaction with warfarin. ${ }^{(15)}$

\section{Mechanism of interaction: notoginseng on warfarin}

Pharmacodynamic: In vitro studies (human, rat) found that both raw and steamed Panax notoginseng exhibits antiplatelet activity, and significantly inhibited platelet aggregation and plasma coagulation. This was positively translated to prolongation of in vivo rat bleeding time at a dosage of $500 \mathrm{mg} / \mathrm{kg}$. ${ }^{(65,66)}$ 